\title{
Use of high-frequency oscillatory ventilation with inhaled nitric oxide in congenital diaphragmatic hernia, omphalocele, and patent ductus arteriosus
}

\author{
Kyu-Nam Kim, Dong-Won Kim, Jae-Chol Shim, Kyo-Sang Kim, and Song-Lark Choi \\ Department of Anesthesiology and Pain Medicine, Hanyang University Hospital, Seoul, Korea
}

Congenital diaphragmatic hernia $(\mathrm{CDH})$ is a defect of the diaphragm and a herniation of the abdominal contents into the thorax leading to pulmonary hypoplasia and severe respiratory disorder. The incidence of $\mathrm{CDH}$ is 1 in 2,500-4,000 live births and a mortality rate of $30-60 \%$ has been reported, despite the development of neonatal care $[1,2]$. CDH is occasionally accompanied by other malformations and in those cases, a significantly higher mortality rate has been reported [1].

A newborn female neonate was delivered vaginally at a gestational age of 30 weeks, with a birth weight of $1.08 \mathrm{~kg}$. A large omphalocele and $\mathrm{CDH}$ were detected on the prenatal ultrasound. The mother was 31 years old, with hyperthyroidism and no history of alcohol, smoking, or other drug use during pregnancy. The neonate was cyanotic and showed no movement at birth. Except for a $6.5 \times 6.8 \mathrm{~cm}$-sized large omphalocele sac containing bowel structure and liver, other malformations were not found (Fig. 1A). Without positive pressure ventilation, intubation was performed in the delivery room. The neonate was admitted to the neonatal intensive care unit (NICU), and the saturation of peripheral oxygen $\left(\mathrm{SpO}_{2}\right)$ on the pulse oximetry was below $60 \%$, despite synchronized intermittent mandatory ventilation with an inspiratory fraction of oxygen $\left(\mathrm{FIO}_{2}\right)$ of 1.0 and surfactant administration. The arterial blood gas analysis (ABGA) read pH 6.78, $\mathrm{PCO}_{2} 102 \mathrm{mmHg}, \mathrm{PO}_{2} 62 \mathrm{mmHg}$, and $\mathrm{BE}-19 \mathrm{mM}$. A $2.05 \mathrm{~mm}$-sized large patent ductus arteriosus (PDA) was found on the transthoracic echocardiography and severe pulmonary hypertension was diagnosed by identification of a retrograde flow of right-to-left shunt and D-shaped ventricular septal wall. The chest radiography showed bowel gases in the left thorax, compatible with $\mathrm{CDH}$ (Fig. 1B). After installing an HFOV device (Calliope $\alpha$, Metran, Saitama, Japan) and 20 ppm inhaled nitric oxide (iNO) for ventilator care, the $\mathrm{SpO}_{2}$ was improved to $90 \%$ and the $\mathrm{ABGA}$ read $\mathrm{pH} 7.03, \mathrm{PCO}_{2} 50 \mathrm{mmHg}$, $\mathrm{PO}_{2} 76 \mathrm{mmHg}$, and $\mathrm{BE}-17 \mathrm{mM}$. The settings for the HFOV were as follows: mean airway pressure (MAP) $11 \mathrm{cmH}_{2} \mathrm{O}$, stroke volume $18 \mathrm{ml}$, frequency $15 \mathrm{~Hz}$, amplitude $30 \mathrm{cmH}_{2} \mathrm{O}$, inspiratory time $33 \%$, and $\mathrm{FIO}_{2} 0.5$. The oxygenation index (MAP $\times$ $\mathrm{FIO}_{2} \times 100 / \mathrm{PaO}_{2}$ ), which offered early prognostic information for the HFOV, was maintained below 8. After 6 days of achieved cardiorespiratory stabilization, the ABGA was $\mathrm{pH} 7.35, \mathrm{PCO}_{2}$ $39 \mathrm{mmHg}, \mathrm{PO}_{2} 61 \mathrm{mmHg}$, and $\mathrm{BE}-4 \mathrm{mM}$ and the demand for dopamine had decreased from $7.5 \mu \mathrm{g} / \mathrm{kg} / \mathrm{min}$ to $5 \mu \mathrm{g} / \mathrm{kg} / \mathrm{min}$, so that the $5 \mu \mathrm{g} / \mathrm{kg} / \mathrm{min}$ dobutamine infusion could be stopped. An operation was scheduled for the primary repair of the $\mathrm{CDH}$. The $\mathrm{CDH}$ repair was conducted prior to the omphalocele repair based on the prediction that if the omphalocele repair were performed preferentially, the increased abdominal pressure would keep the herniated abdominal content from returning into the abdomen.

To avoid changing the ventilator settings, the operation was conducted in the NICU while applying HFOV with iNO. General anesthesia was induced with intravenous $1 \mathrm{mg}$ ketamine, $0.6 \mathrm{mg}$ rocuronium, and a $0.5 \mu \mathrm{g} / \mathrm{kg} / \mathrm{hr}$ remifentanil infusion. For hemodynamic support, $5 \mu \mathrm{g} / \mathrm{kg} / \mathrm{min}$ of dopamine were

Corresponding author: Dong-Won Kim, M.D., Ph.D., Department of Anesthesiology and Pain Medicine, Hanyang University Hospital, 222, Wangsimni-ro, Seongdong-gu, Seoul 133-070, Korea. Tel: 82-2-2290-8680, Fax: 82-2-2299-8692, E-mail: dongwkim@hanyang.ac.kr

(c) This is an open-access article distributed under the terms of the Creative Commons Attribution Non-Commercial License (http:// creativecommons.org/licenses/by-nc/3.0/), which permits unrestricted non-commercial use, distribution, and reproduction in any medium, provided the original work is properly cited. 

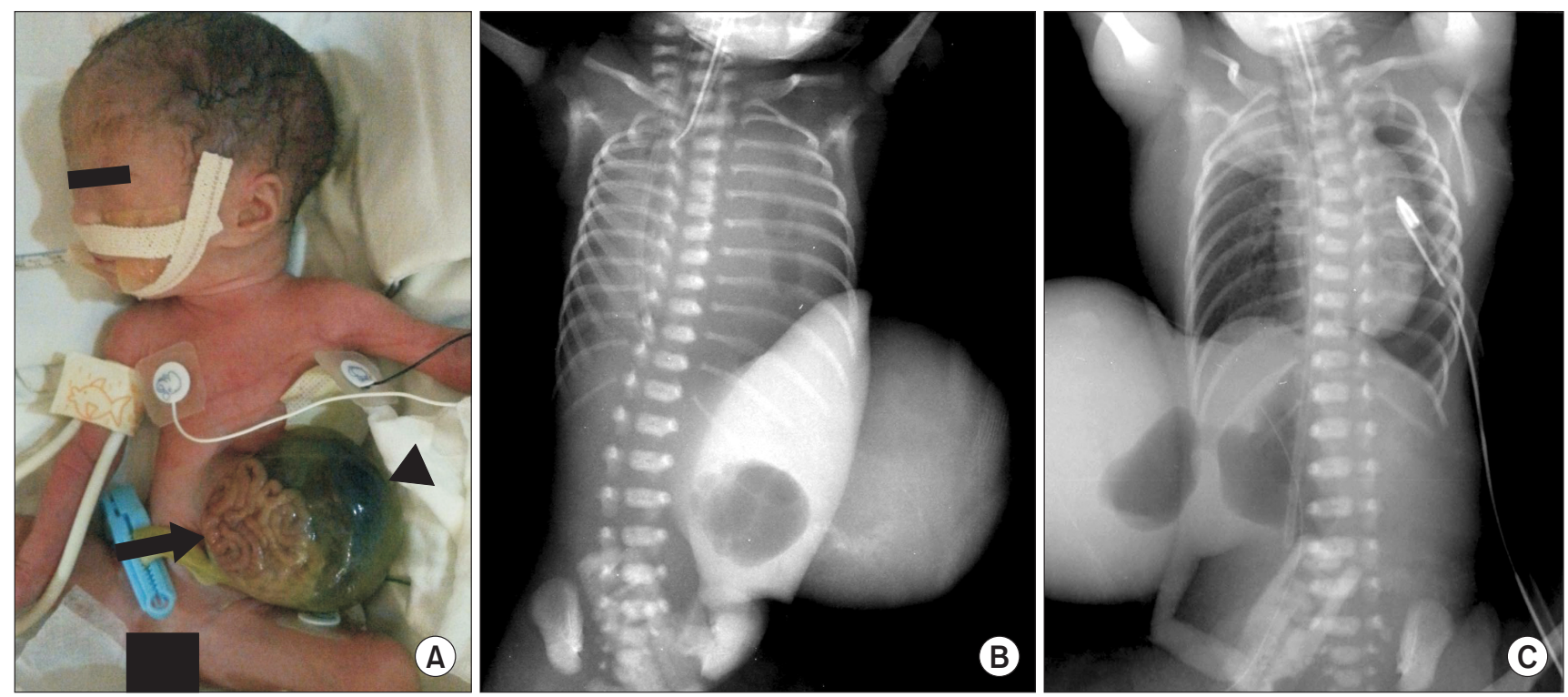

Fig. 1. (A) Picture of the patient shows bowel structure (black arrow) and liver (black arrow head) in $6.5 \times 6.8 \mathrm{~cm}$-sized large omphalocele sac. (B) Chest radiography shows bowel gases in the left thorax compatible with congenital diaphragmatic hernia and total atelectasis of the right lung due to herniated abdominal content. (C) Postoperative chest radiography shows the herniated abdominal content having returned to the abdominal cavity and the left thorax filled with air. A chest tube is inserted to prevent the deterioration of the pneumothorax.

infused. The primary repair of the hernia defect was performed through an abdominal approach with a prosthetic patch, and the herniated stomach, duodenum and spleen in the left thorax were withdrawn to the abdominal cavity. To prevent a loss of water and heat, the omphalocele sac was covered with a plastic bag during the $\mathrm{CDH}$ operation. During the surgical intervention, the hemodynamic signs were stable and the $\mathrm{SpO}_{2}$ was kept above $90 \%$. After closure of the $\mathrm{CDH}$ was performed, the $\mathrm{SpO}_{2}$ rose to $97 \%$ and the mean blood pressure gradually increased by about $5 \mathrm{mmHg}$, without other treatment. The postoperative chest radiography showed that the left thorax was filled with air (Fig. 1C). To maintain the oxygenation index below 8 , the MAP and $\mathrm{FIO}_{2}$ could be decreased to $9 \mathrm{cmH}_{2} \mathrm{O}$ and 0.35 , respectively.

Because the increased abdominal pressure caused by the reduction of the intestinal content of the $\mathrm{CDH}$ could impair the ventilation, the venous return, and the cardiac output, a staged repair with a prosthetic silo was conducted for omphalocele treatment 4 days later. The general anesthesia was performed in the same way except that no dopamine infusion was used. Since the reduction of the herniated abdominal content in the omphalocele sac caused an increase in the abdominal pressure, the HFOV was applied continuously after the surgery, owing to the possibility of respiratory depression caused by the increased abdominal pressure. The patient was under close observation in the NICU until the abdominal content in the omphalocele sac gradually returned to the abdominal cavity by gravity.

$\mathrm{CDH}$ is one of the most challenging congenital disorders for anesthesia because of the difficulty of respiratory care during the surgery. In this case, the conventional positive pressure ventilation became ineffective due to high peak inspiratory pressure (PIP), $\mathrm{CO}_{2}$ retention, and severe acidosis. Excessive distending pressure, volutrauma, repetitive collapse, and re-expansion of the lung are causes of lung injury and if the PIP is over $28 \mathrm{cmH}_{2} \mathrm{O}$, other treatment should be considered [2]. To solve these problems, gentle ventilation and a permissive hypercapnia strategy were induced. One approach for these methods is HFOV. HFOV employs a small tidal volume less than the dead space to acquire sufficient alveolar ventilation with minimal volume change, and to improve the alveolar recruitment without barotrauma and overinflation of the lung [3]. It can also be applied safely during anesthesia. Because the constant distending pressure from HFOV decreases the venous return and cardiac output [3], close observation of the invasive blood pressure was performed and the stroke volume was adjusted based on the eight-rib expansion of the side contralateral to the defect from the chest radiography which was acquired immediately after the surgery in the NICU. To reduce the risks from transport and maintain the continuity of the intensive care resulting in increased survival and reduced complications [4], the operation was performed in the NICU.

The degree of pulmonary hypoplasia and pulmonary hypertension is the most important prognostic factor for $\mathrm{CDH}$. A decreased number of vascular branches with increased adventitial and medial thickness and decreased cross-sectional area of the pulmonary arteries due to lung hypoplasia result in pulmonary hypertension and right heart failure [2]. Surgical repair is delayed until the clinical conditions are sufficiently stable to im- 
prove respiratory compliance, and the purpose of preoperative stabilization is the resolution of pulmonary hypertension. Nitric oxide is effective at reducing persistent pulmonary hypertension in newborns through selective pulmonary vasodilatation. Therefore iNO should be considered as the first therapeutic choice, based on recent studies which reported that iNO with HFOV reduced the need for extracorporeal membrane oxygenation and improved survival odds $[2,5]$. In addition, iNO should also be used to control a right-to-left shunt worsened by a large ret- rograde flow from PDA, caused by pulmonary hypertension in this case.

In conclusion, surgical intervention in our patient with $\mathrm{CDH}$, omphalocele and PDA was safely conducted while the patient received HFOV with iNO. Patients receiving HFOV and iNO should be operated in the NICU in order to reduce the risks from transport and to maintain the continuity of the intensive care, resulting in increased survival odds and reduced complications.

\section{References}

1. Zaiss I, Kehl S, Link K, Neff W, Schaible T, Sütterlin M, et al. Associated malformations in congenital diaphragmatic hernia. Am J Perinatol 2011; 28: 211-8.

2. Reiss I, Schaible T, van den Hout L, Capolupo I, Allegaert K, van Heijst A, et al. Standardized postnatal management of infants with congenital diaphragmatic hernia in Europe: the CDH EURO Consortium consensus. Neonatology 2010; 98: 354-64.

3. Arnold JH. High-frequency ventilation in the pediatric intensive care unit. Pediatr Crit Care Med 2000; 1: 93-9.

4. Lago P, Meneghini L, Chiandetti L, Tormena F, Metrangolo S, Gamba P. Congenital diaphragmatic hernia: intensive care unit or operating room? Am J Perinatol 2005; 22: 189-97.

5. Ng GY, Derry C, Marston L, Choudhury M, Holmes K, Calvert SA. Reduction in ventilator-induced lung injury improves outcome in congenital diaphragmatic hernia? Pediatr Surg Int 2008; 24: 145-50. 